\title{
Challenges in $\beta_{3}$-adrenoceptor agonist drug development
}

\author{
Jonathan R. S. Arch
}

Ther Adv Endocrinol Metab

(2011) 2(2) 59-64 DOI: $10.1177 /$ 2042018811398517

(C) The Author(s), 2011 Reprints and permissions: http://www.sagepub.co.uk/ journalsPermissions.nav

\section{Historical setting}

In the latter part of the 1970s and the early 1980 s three pharmaceutical companies were attempting to design drugs that would retain the thermogenic and antiobesity activity in rodents of nonselective sympathomimetic agents, while lacking the undesirable effects elicited by such agents, in particular increased heart rate and tremor. These companies were Lilly [Yen et al. 1984] Beecham Pharmaceuticals (for which this author worked) [Arch et al. 1984b], and Hoffman-La-Roche [Meier et al. 1984]. Others revealed their interest a little later [Holloway et al. 1991]. From this work, Beecham Pharmaceuticals identified compounds that activated an 'atypical' $\beta$-adrenoceptor in rodent brown and white adipocytes [Arch et al. 1984a]. From 1974 Zaagsma and colleagues had gathered evidence that the rat white adipocyte $\beta$-adrenoceptor was atypical but they had used only antagonists [Harms et al. 1974]. Antagonists mostly display low potency at the atypical $\beta$-adrenoceptor compared with $\beta_{1^{-}}$and $\beta_{2}$-adrenoceptors. Even before Zaagsma's work, Furchgott had reviewed antagonist data that showed that the $\beta$-adrenoceptor in various parts of the gut is atypical [Furchgott, 1972]. Tan and Curtis-Prior suggested in 1983 that the adipocyte receptor should be called the $\beta_{3}$-adrenoceptor, but it was not until 1989 that I argued strongly for the use of this name to describe the atypical adipocyte $\beta$-adrenoceptor [Arch, 1989]. Soon afterwards, the human $\beta_{3}$-adrenoceptor was cloned [Emorine et al. 1989] and subsequent work showed that the rodent $\beta_{3}$-adrenoceptor is identical to the atypical $\beta$-adrenoceptor found in both adipocytes and the gut. It also became clear that the $\beta_{3}$-adrenoceptor is primarily responsible for thermogenesis (increased energy expenditure) and fat loss in response to sympathetic stimulation in obese rodents. Fuller versions of this sequence of events have been published previously [Arch, 2008; Arch and Kaumann, 1993].

Some words of caution are needed for those who have not followed events over the years: the terms 'atypical $\beta$-adrenoceptor' and a 'third $\beta$-adrenoceptor' [Kaumann, 1989] have been used to describe a $\beta$-adrenoceptor (or $\beta$-adrenoceptors) that is not the $\beta_{3}$-adrenoceptor. In particular, there is a form of the $\beta_{1}$-adrenoceptor that has atypical pharmacology and in some respects is similar to that of the $\beta_{3}$-adrenoceptor. For example, both receptors are stimulated by certain 'nonconventional $\beta$-blockers', such as (-)-pindolol, at concentrations much higher than those that block $\beta_{1}$ - and $\beta_{2}$-adrenoceptors, and both receptors have low affinity for conventional $\beta$ blockers. One difference, however, is that the original (arylethanolamine) $\beta_{3}$-adrenoceptor agonists have low potency at the atypical $\beta_{1}$-adrenoceptor [Brahmadevara et al. 2003; Arch, 2002; Brawley et al. 2000]. After being called the 'third heart $\beta$-adrenoceptor' [Kaumann, 1989], the atypical $\beta_{1}$-adrenoceptor was for a few years known as the $\beta_{4}$-adrenoceptor [Kaumann, 1997] but studies in knockout mice demonstrated that its pharmacological detection depended on the presence of the $\beta_{1}$ - but not the $\beta_{3}$-adrenoceptor gene [Kaumann et al. 2001, 1998; Cohen et al. 2000; Konkar et al. 2000]. Even though it is not a genetically distinct $\beta$-adrenoceptor, this 'low affinity $\beta_{1}$-adrenoceptor,' as it is now usually called, could conceivably offer a target for drugs, especially for the treatment of cardiovascular disease [Arch, 2004].

Returning to $\beta_{3}$-adrenoceptor agonists, it was soon discovered that they are remarkably effective in rodent models of type 2 diabetes, as well as obesity [Sennitt et al. 1985]. This activity is most
Correspondence to: Jonathan R. S. Arch Clore Laboratory, University of Buckingham, Hunter Street,

Buckingham MK18 1EG, UK jon.archa buckingham.ac.uk 
likely a consequence of their ability to increase fatty acid oxidation and thereby lower the concentration of fatty acid metabolites, such as fatty acyl CoA, diacylglycerol and ceramide [Darimont et al. 2004; Wilson et al. 1987]. These metabolites activate certain protein kinase C isozymes, such as PKC- $\theta$, causing them to phosphorylate key serine residues of insulin receptor substrate-1. Fatty acids and their metabolites may also play a role in the inflammatory response through similar mechanisms [Schwartz et al. 2010; Kennedy et al. 2009; Schenk et al. 2008]. Antilipolytic agents or ablation of $\beta_{3}$-adrenoceptors in white adipose tissue reduces or prevents the thermogenic activity of $\beta_{3}$-adrenoceptor agonists [Arch, 2011, 2008]. However, it may be that while the 'push' of fatty acid supply is required for thermogenesis, this actually reduces insulin sensitivity because it tends to raise fatty acid metabolite levels. It is only when the 'pull' of increased fatty acid oxidation capacity exceeds the push that fatty acid metabolite levels fall and insulin sensitivity improves. Indeed, $\beta$-adrenoceptor agonists and natural catecholamines raise plasma nonesterified fatty acid (NEFA) levels and exacerbate insulin resistance initially. It is only on repeated dosing that NEFA levels fall and insulin sensitivity improves [Sugimoto et al. 2005; Liu et al. 1998; Virtanen et al. 1997]. This is at least partly because the capacity for fatty acid oxidation increases with repeated dosing; it is also possible that lipolysis decreases.

\section{Translation from rodents to humans}

Why then, over 25 years since the first $\beta_{3}$-adrenoceptor agonists were identified, is one not being used to treat obesity or type 2 diabetes in humans? The first setback for this author came with the discovery that the same compounds that were as effective as lipolytic agents in rodent white adipocytes had little or no lipolytic effect in human adipocytes. There were two possible explanations: either the $\beta_{3}$-adrenoceptor was poorly expressed in human white adipocytes, or those compounds that activated the rodent receptor had little efficacy at the human receptor. Both explanations turned out to be true. When the human and rodent receptors were cloned and expressed in cell lines it became clear that their pharmacologies differed. Moreover, lipolysis in human white adipocyte was mediated mainly by classical $\beta$-adrenoceptors [Lafontan and Berlan, 1993].
The problem of different $\beta_{3}$-adrenoceptor agonists being required to activate the human and rodent receptor seemed like a relatively simple exercise in medicinal chemistry, using the then new screening technologies based on human cloned receptors. At SmithKline Beecham, we did not concern ourselves with using tool compounds to demonstrate efficacy in rodent models of obesity and diabetes; that had already been done and it did not worry us that our human $\beta_{3}$-adrenoceptor-selective compounds could not be used in rodents. However, we were confronted by the problem that none of the compounds that we identified as highly selective for the human receptor displayed good oral bioavailability. This is clearly a problem that was encountered by others, as illustrated by a stream of publications by authors from Merck that have a strong emphasis on the need to achieve good oral bioavailability [Goble et al. 2010; Stearns et al. 2002].

A few $\beta_{3}$-adrenoceptor agonists that were both highly selective and had good oral bioavailability and pharmacokinetics for an oral drug intended to raise energy expenditure over $24 \mathrm{~h}$ may have failed for reasons of toxicity or perhaps because they were $\beta_{1^{-}}$or $\beta_{2}$-adrenoceptor antagonists, which bring their own problems. With other compounds there may have been some compromise on selectivity as agonists to achieve suitable oral bioavailability and pharmacokinetic profile. In the experience of this author, even slight agonist activity at cloned $\beta_{1^{-}}$or $\beta_{2}$-adrenoceptors may translate into significant agonist activity in human right atrial appendage [Sennitt et al. 1998]. These compounds may therefore have failed in the clinic owing to their $\beta_{1}$ - or $\beta_{2}$-adrenoceptor-mediated cardiovascular effects. Added to this they may have elicited some cardiovascular effects via $\beta_{3}$-adrenoceptors in the heart and in vascular smooth muscle. The article by Bhadada et al. (2011) discusses the role of $\beta_{3}$-adrenoceptors in these tissues.

The other question is whether $\beta_{3}$-adrenoceptors play the same role in humans as in rodents. Studies using highly selective $\beta_{3}$-adrenoceptor agonists suggested that there are functional $\beta_{3}$-adrenoceptors in human white adipocytes but their role is minor [Sennitt et al. 1998]. Fortunately, human brown adipocytes express $\beta_{3}$-adrenoceptors [Deng et al. 1997; Krief et al. 1993], but is there enough brown adipose tissue 
in humans to make these a suitable target for drugs?

Compared with humans, rodents have a much higher surface area to volume ratio, they are more exposed to variations in ambient temperature and they do not wear clothes. They depend upon sympathetically driven 'nonshivering thermogenesis' to maintain body temperature when the ambient temperature is below the thermoneutral range. A significant proportion of nonshivering thermogenesis takes place in brown adipose tissue and is mediated primarily by the $\beta_{3}$-adrenoceptor. Moreover, when heat loss increases, for example when ambient temperature falls, the capacity for nonshivering thermogenesis increases and most - some say all - of this increased capacity is in brown adipose tissue [Golozoubova et al. 2006]. A single dose of a $\beta_{3}$-adrenoceptor agonist can at least double energy expenditure in a mouse maintained at about $21^{\circ} \mathrm{C}$, and in $o b / o b$ mice, which have low sympathetic activity (or if the capacity for thermogenesis has been increased by keeping animals in a cold environment and then they are returned to the warm to inhibit endogenous sympathetic activity) the increase can be much greater [Feldmann et al. 2009; Wilson et al. 1984]. By contrast in humans, sympathomimetic agents raise energy expenditure by no more than about $30 \%$ [Schiffelers et al. 2000], whilst $\beta_{3}$-adrenoceptor agonists may achieve less than 10\% [van Baak et al. 2002].

There has long been evidence that adult humans have some brown adipose tissue [Lean, 1989, Heaton, 1972]. The conventional view, however, has been that only babies have a significant amount of the tissue. For some, this provided an easy explanation for the failure of $\beta_{3}$-adrenoceptor agonists as drugs for obesity or type 2 diabetes. This belief has been challenged in recent years by reports that active brown adipose tissue had been detected in adult humans using positron-emission tomography to detect uptake of ${ }^{18}$ F-fluorodeoxyglucose [Nedergaard et al. 2007]. Such work was first conducted by oncologists to detect tumours. For oncologists, brown adipose tissue is a nuisance: tumours do not form symmetrically across the shoulders and down each side of the spine! There is a strong relationship between the activity of brown adipose tissue in humans and their percentage body fat [van Marken Lichtenbelt et al. 2009]. This raises the possibility that low brown adipose tissue activity is a cause of obesity. Alternative explanations should not be discounted: low sympathetic activity may be a cause (or marker) of obesity, and brown adipose tissue activity a marker of sympathetic activity.

Whatever the explanation for the inverse relationship between brown adipose tissue activity and obesity, a key question is whether there is enough brown adipose tissue in obese humans to make it a target for drugs for obesity or diabetes. It is likely that more than half of all men and women have $10 \mathrm{~g}$ or more of brown adipose tissue [Cypess et al. 2009]. Unfortunately, this means that most obese people, who are in the lower half, have less than $10 \mathrm{~g}$ of fat. Calculations suggest that full activation of less than $10 \mathrm{~g}$ of brown adipose tissue would increase energy expenditure by less than $4 \%$. Therefore, if $\beta_{3}$-adrenoceptor agonists are to depend on brown adipose tissue to achieve useful efficacy, not only must they be delivered to brown adipose tissue effectively, but probably also the amount or oxidative capacity of brown adipose tissue in the typical obese person must be increased.

One way to increase the effective amount of brown adipose tissue may simply be to give a $\beta_{3}$-adrenoceptor agonist chronically. This works in rodents and it may work in humans because patients with catecholamine-secreting tumours have more brown adipose tissue than most people [Lean, 1989]. Another approach might be to coadminister a $\beta_{3}$-adrenoceptor agonist with another drug. For example, a $\beta_{3}$-adrenoceptor agonist might be combined with an agonist of the bile acid receptor TGR5, which is expressed in brown adipose, among other tissues, and like the $\beta_{3}$-adrenoceptor is coupled to $\mathrm{G}_{\mathrm{s}}$ [Watanabe et al. 2006].

A rather different approach might address the problem of both drug delivery and activation of brown adipose tissue. Zinc $\alpha_{2}$-glycoprotein (ZAG), also known as lipid-mobilizing factor, is a protein secreted by some tumours that appears to be partly responsible for cachexia. It is also secreted by white adipose tissue, with there being lower blood levels in obesity. ZAG has similar efficacy in rodent models of obesity and type 2 diabetes to $\beta_{3}$-adrenoceptor agonists, except that it appears more like the $\beta_{2}$-adrenoceptor agonist clenbuterol in its ability to increase skeletal muscle mass [Russell and Tisdale, 2010]. ZAG reduces metabolic efficiency like 
$\beta_{3}$-adrenoceptor agonists do and it is claimed to actually be a $\beta_{3}$-adrenoceptor agonist [Russell et al. 2002]. However, the lipolytic effects of isoprenaline and a $\beta_{3}$-adrenoceptor agonist were reduced to similar extents in adipocytes from ZAG-deficient mice, suggesting that ZAG enhances $\beta$-adrenoceptor signalling [Rolli et al. 2007]. ZAG increases $\mathrm{Gs}_{\alpha}$ expression [Islam-Ali et al. 2001], which could be a way of achieving this. Interestingly, ZAG has not been reported to increase energy expenditure acutely in the way that a $\beta_{3}$-adrenoceptor agonist does. So while it may not strictly be a $\beta_{3}$-adrenoceptor agonist, ZAG may activate brown adipose tissue and perhaps increase $\beta_{3}$-adrenoceptor expression. It would have to be injected, side-stepping the issue of oral bioavailability, and could be modified to solve any pharmacokinetic (and patent protection) issue.

\section{Alternative directions}

I have focussed on the challenges of developing $\beta_{3}$-adrenoceptor agonists for metabolic diseases, especially obesity and diabetes. $\beta_{3}$-adrenoceptors offer potential targets for other diseases. The article by Bhadada et al. (2011) discusses their relevance to cardiometabolic diseases and the potential of antagonists as well as agonists. It also alludes to the point that different agonists (of any receptor) may activate different signalling pathways and so have different therapeutic benefits [Evans et al. 2010], although the suggestion that this might be due to selective activation of the $\beta_{3 \mathrm{a}^{-}}$and $\beta_{3 \mathrm{~b}}$-adrenoceptor splice variants is unlikely because no variants have been detected in humans [Evans et al. 1999]. Others have focussed on the potential of $\beta_{3}$-adrenoceptor agonists for the treatment of irritable bladder and other urinogenital disorders [Ursino et al. 2009].

Some of these other indications have the advantage that the $\beta_{3}$-adrenoceptor is more highly expressed in the relevant human tissues than in 'metabolic tissues'. There remains, however, the issue that compounds selective for the human $\beta_{3}$-adrenoceptor tend not to have good oral bioavailability or a long plasma half life. Moreover, there may now be limited 'chemical space' for designing new patentable molecules.

Some targets have been known for over 20 years before they have yielded a drug, so there is still hope, but the $\beta_{3}$-adrenoceptor will certainly not yield to the faint hearted.

\section{Acknowledgement}

I thank Mike Cawthorne for checking the manuscript and correcting some of my hazy memories.

\section{Funding}

This research received no specific grant from any funding agency in the public, commercial, or notfor-profit sectors.

\section{Conflict of interest statement \\ None declared.}

\section{References}

Arch, J.R. (2002) $\beta_{3}$-Adrenoceptor agonists: potential, pitfalls and progress. Eur F Pharmacol 440: 99-107.

Arch, J.R. (2004) Do low-affinity states of $\beta$-adrenoceptors have roles in physiology and medicine? $\mathrm{Br} \mathcal{F}$ Pharmacol 143: 517-518.

Arch, J.R. (2008) The discovery of drugs for obesity, the metabolic effects of leptin and variable receptor pharmacology: Perspectives from $\beta_{3}$-adrenoceptor agonists. Naunyn Schmiedebergs Arch Pharmacol 378: 225-240.

Arch, J.R.S. (1989) The brown adipocyte $\beta$-adrenoceptor. Proc Nutr Soc 48: 215-223.

Arch, J.R.S. (2011) Thermogenesis and related metabolic targets in anti-diabetic therapy, In: Schwanstecher, M. (ed.). Handbook of Experimental Pharmacology - Diabetes, Springer: Heidelberg, in press.

Arch, J.R.S., Ainsworth, A.T., Cawthorne, M.A., Piercy, V., Sennitt, M.V., Thody, V.E. et al. (1984a) Atypical $\beta$-adrenoceptor on brown adipocytes as target for anti-obesity drugs. Nature 309: 163-165.

Arch, J.R.S., Ainsworth, A.T., Ellis, R.D.M., Piercy, V., Thody, V.E., Thurlby, P.L. et al. (1984b) Treatment of obesity with thermogenic $\beta$-adrenoceptor agonists: Studies on BRL 26830A in rodents. Int $\mathcal{F}$ Obes 8(Suppl. 1): 1-11.

Arch, J.R.S. and Kaumann, A.J. (1993) $\beta_{3}$ and atypical $\beta$-adrenoceptors. Med Res Rev 13: 663-729.

Bhadada S.V., Patel, B.M., Mehta, A.A. and Goyal R.K. (2011) $\beta_{3}$ receptors: role in cardiometabolic disorders. Ther Adv Endocrinol Metab. E-print 10.1177/ 2042018810390259.

Brahmadevara, N., Shaw, A.M. and MacDonald, A. (2003) Evidence against $\beta_{3}$-adrenoceptors or low affinity state of $\beta_{1}$-adrenoceptors mediating relaxation in rat isolated aorta. Br F Pharmacol 138: 99-106.

Brawley, L., Shaw, A.M. and MacDonald, A. (2000) $\beta_{1^{-}}, \beta_{2^{-}}$and atypical $\beta$-adrenoceptor-mediated relaxation in rat isolated aorta. Br $\mathcal{F}$ Pharmacol

129: 637-644. 
Cohen, M.L., Bloomquist, W., Ito, M. and Lowell, B.B. (2000) $\beta_{3}$ receptors mediate relaxation in stomach fundus whereas a fourth $\beta$ receptor mediates tachycardia in atria from transgenic $\beta_{3}$ receptor knockout mice. Receptors Channels 7: 17-23.

Cypess, A.M., Lehman, S., Williams, G., Tal, I., Rodman, D., Goldfine, A.B. et al. (2009)

Identification and importance of brown adipose tissue in adult humans. N Engl F Med 360: 1509-1517.

Darimont, C., Turini, M., Epitaux, M., Zbinden, I., Richelle, M., Montell, E. et al. (2004) ß3-adrenoceptor agonist prevents alterations of muscle diacylglycerol and adipose tissue phospholipids induced by a cafeteria diet. Nutr Metab (Lond) 1: 4.

Deng, C., Paoloni-Giacobino, A., Kuehne, F., Boss, O., Revelli, J.-P., Moinat, M. et al. (1997) Respective degree of expression of $\beta_{1^{-}}, \beta_{2^{-}}$and $\beta_{3}$-adrenoceptors in human brown and white adipose tissues. Br f Pharmacol 118: 929-934.

Emorine, L.J., Marullo, S., Briend-Sutren, M.M., Patey, G., Tate, K., Delavier-Klutchko, C. et al. (1989) Molecular characterization of the human $\beta_{3}$-adrenergic receptor. Science 245: 1118-1121.

Evans, B.A., Papaioannou, M., Hamilton, S. and Summers, R.J. (1999) Alternative splicing generates two isoforms of the $\beta_{3}$-adrenoceptor which are differentially expressed in mouse tissues. Br $\mathcal{F}$ Pharmacol 127: 1525-1531.

Evans, B.A., Sato, M., Sarwar, M., Hutchinson, D.S. and Summers, R.J. (2010) Ligand-directed signalling at $\beta$-adrenoceptors. Br $\mathcal{F}$ Pharmacol 159: $1022-1038$.

Feldmann, H.M., Golozoubova, V., Cannon, B. and Nedergaard, J. (2009) UCP1 ablation induces obesity and abolishes diet-induced thermogenesis in mice exempt from thermal stress by living at thermoneutrality. Cell Metab 9: 203-209.

Furchgott, R.F. (1972) The classification of adrenoceptors (adrenergic receptors). An evaluation from the standpoint of receptor theory, In: Blaschko, H. and Muecholl, E. (eds). Catecholamines, Springer-Verlag: New York, pp. 283-335..

Goble, S.D., Wang, L., Howell, K.L., Bansal, A., Berger, R., Brockunier, L. et al. (2010) Heterocyclic acetamide and benzamide derivatives as potent and selective $\beta_{3}$-adrenergic receptor agonists with improved rodent pharmacokinetic profiles. Bioorg Med Chem Lett 20: 1895-1899.

Golozoubova, V., Cannon, B. and Nedergaard, J. (2006) UCP1 is essential for adaptive adrenergic nonshivering thermogenesis. Am $\mathcal{F}$ Physiol Endocrinol Metab 291: E350-E357.

Harms, H.H., Zaagsma, J. and Van der Wal, B. (1974) $\beta$-adrenoceptor studies. III. On the $\beta$-adrenoceptors in rat adipose tissue. Eur F Pharmacol 25: 87-91.

Heaton, J.M. (1972) The distribution of brown adipose tissue in the human. $\mathcal{F}$ Anat 112: 35-39.
Holloway, B.R., Howe, R., Rao, B.S., Stribling, D., Mayers, R.M., Briscoe, M.G. et al. (1991) ICI D7114 a novel selective $\beta$-adrenoceptor agonist selectively stimulates brown fat and increases whole-body oxygen consumption. Br F Pharmacol 104: 97-104.

Islam-Ali, B., Khan, S., Price, S.A. and Tisdale, M.J. (2001) Modulation of adipocyte G-protein expression in cancer cachexia by a lipid-mobilizing factor (LMF). Br f Cancer 85: 758-763.

Kaumann, A.J. (1989) Is there a third heart $\beta$-adrenoceptor? Trends Pharmacol Sci 10: 316-320.

Kaumann, A.J. (1997) Four $\beta$-adrenoceptor subtypes in the mammalian heart. Trends Pharmacol Sci 18: $70-76$.

Kaumann, A.J., Engelhardt, S., Hein, L., Molenaar, P. and Lohse, M. (2001) Abolition of (-)-CGP 12177-evoked cardiostimulation in double

$\beta_{1} / \beta_{2}$-adrenoceptor knockout mice. Obligatory role of $\beta_{1}$-adrenoceptors for putative $\beta_{4}$-adrenoceptor pharmacology. Naunyn Schmiedebergs Arch Pharmacol 363: 87-93.

Kaumann, A.J., Preitner, F., Sarsero, D., Molenaar, P., Revelli, J.P. and Giacobino, J.P. (1998) (-)-CGP 12177 causes cardiostimulation and binds to cardiac putative $\beta_{4}$-adrenoceptors in both wild-type and $\beta_{3}$-adrenoceptor knockout mice. Mol Pharmacol 53: 670-675.

Kennedy, A., Martinez, K., Chuang, C.C., LaPoint, K. and McIntosh, M. (2009) Saturated fatty acidmediated inflammation and insulin resistance in adipose tissue: Mechanisms of action and implications. F Nutr 139: 1-4.

Konkar, A.A., Zhai, Y. and Granneman, J.G. (2000) $\beta_{1}$-adrenergic receptors mediate $\beta_{3}$-adrenergicindependent effects of CGP 12177 in brown adipose tissue. Mol Pharmacol 57: 252-258.

Krief, S., Lonnqvist, F., Raimbault, S., Baude, B., Van Spronson, A., Arner, P. et al. (1993) Tissue distribution of $\beta_{3}$-adrenergic receptor $\mathrm{mRNA}$ in man. F Clin Invest 91: 344-349.

Lafontan, M. and Berlan, M. (1993) Fat cell adrenergic receptors and the control of white and brown fat cell function. F Lipid Res 34: 1057-1091.

Lean, M.E. (1989) Brown adipose tissue in humans. Proc Nutr Soc 48: 243-256.

Liu, X., Perusse, F. and Bukowiecki, L.J. (1998)

Mechanisms of the antidiabetic effects of the

$\beta_{3}$-adrenergic agonist CL-316243 in

obese Zucker-ZDF rats. Am $\mathcal{F}$ Physiol

274: R1212-R1219.

Meier, M.K., Alig, L., Burgi-Saville, M.E. and Muller, M. (1984) Phenethanolamine derivatives with calorigenic and antidiabetic qualities. Int $\mathcal{f}$ Obesity 8(Suppl. 1): 215-225.

Nedergaard, J., Bengtsson, T. and Cannon, B. (2007) Unexpected evidence for active brown adipose tissue in adult humans. Am $\mathcal{F}$ Physiol Endocrinol Metab 293: E444-E452. 
Rolli, V., Radosavljevic, M., Astier, V., Macquin, C., Castan-Laurell, I., Visentin, V. et al. (2007) Lipolysis is altered in MHC class I zinc- $\alpha_{2}$-glycoprotein deficient mice. FEBS Lett 581: 394-400.

Russell, S.T., Hirai, K. and Tisdale, M.J. (2002) Role of $\beta_{3}$-adrenergic receptors in the action of a tumour lipid mobilizing factor. Br f Cancer 86: 424-428.

Russell, S.T. and Tisdale, M.J. (2010) Antidiabetic properties of zinc- $\alpha_{2}$-glycoprotein in ob/ob mice. Endocrinology 151: 948-957.

Schenk, S., Saberi, M. and Olefsky, J.M. (2008) Insulin sensitivity: Modulation by nutrients and inflammation. F Clin Invest 118: 2992-3002.

Schiffelers, S.L., Blaak, E.E., Saris, W.H. and van Baak, M.A. (2000) In vivo $\beta_{3}$-adrenergic stimulation of human thermogenesis and lipid use. Clin Pharmacol Ther 67: 558-566.

Schwartz, E.A., Zhang, W.Y., Karnik, S.K., Borwege, S., Anand, V.R., Laine, P.S. et al. (2010) Nutrient modification of the innate immune response: A novel mechanism by which saturated fatty acids greatly amplify monocyte inflammation. Arterioscler Thromb Vasc Biol 30: 802-808.

Sennitt, M.V., Arch, J.R.S., Levy, A.L., Simson, D.L., Smith, S.A. and Cawthorne, M.A. (1985) Antihyperglycaemic action of BRL 26830, a novel $\beta$-adrenoceptor agonist, in mice and rats. Biochem Pharmacol 34: 1279-1285.

Sennitt, M.V., Kaumann, A.J., Molenaar, P., Beeley, L.J., Young, P.W., Kelly, J. et al. (1998) The contribution of classical $\left(\beta_{1 / 2^{-}}\right)$and atypical $\beta$-adrenoceptors to the stimulation of human white adipocyte lipolysis and right atrial appendage contraction by novel $\beta_{3}$-adrenoceptor agonists of differing selectivities. F Pharmacol Exp Ther 285: 1084-1095.

Stearns, R.A., Miller, R.R., Tang, W., Kwei, G.Y., Tang, F.S., Mathvink, R.J. et al. (2002) The pharmacokinetics of a thiazole benzenesulfonamide $\beta_{3}$-adrenergic receptor agonist and its analogs in rats, dogs, and monkeys: Improving oral bioavailability. Drug Metab Dispos 30: 771-777.

Sugimoto, T., Ogawa, W., Kasuga, M. and Yokoyama, Y. (2005) Chronic effects of AJ-9677 on energy expenditure and energy source utilization in rats. Eur f Pharmacol 519: 135-145.

Ursino, M.G., Vasina, V., Raschi, E., Crema, F. and De Ponti, F. (2009) The $\beta_{3}$-adrenoceptor as a therapeutic target: Current perspectives. Pharmacol Res 59: 221-234.

van Baak, M.A., Hul, G.B., Toubro, S., Astrup, A., Gottesdiener, K.M., DeSmet, M. et al. (2002) Acute effect of L-796568, a novel $\beta_{3}$-adrenergic receptor agonist, on energy expenditure in obese men. Clin Pharmacol Ther 71: 272-279.

van Marken Lichtenbelt, W.D., Vanhommerig, J.W., Smulders, N.M., Drossaerts, J.M., Kemerink, G.J., Bouvy, N.D. et al. (2009) Cold-activated brown adipose tissue in healthy men. $N$ Engl F Med 360: 1500-1508.

Virtanen, K.A., Rouru, J., Hanninen, V., Savontaus, E., Rouvari, T., Teirmaa, T. et al. (1997) Chronic treatment with BRL 35135 potentiates the action of insulin on lipid metabolism. Eur F Pharmacol 332: 215-218.

Watanabe, M., Houten, S.M., Mataki, C., Christoffolete, M.A., Kim, B.W., Sato, H. et al. (2006) Bile acids induce energy expenditure by promoting intracellular thyroid hormone activation. Nature 439: 484-489.

Wilson, S., Arch, J.R. and Thurlby, P.L. (1984) Genetically obese C57BL/6 ob/ob mice respond normally to sympathomimetic compounds. Life Sci 35: 1301-1309.

Wilson, S., Thurlby, P.L. and Arch, J.R. (1987) Substrate supply for thermogenesis induced by the $\beta$ adrenoceptor agonist BRL 26830A. Can F Physiol Pharmacol 65: 113-119.

Yen, T.T., McKee, M.M. and Stamm, N.B. (1984) Thermogenesis and weight control. Int $\mathcal{F}$ Obesity 8(Suppl. 1): 65-78. 